\title{
Las fuentes del ordenamiento jurídico español en la jurisprudencia constitucional
}

José Julio Fernández Rodríguez

\section{Introducción}

Con la expresión fuentes del Derecho se acude a una metáfora para indicar o bien los posibles orígenes de las normas jurídicas (que sería el sentido que más se corresponde al significado de la referencia de la metáfora -lugar donde nace agua-), o bien las normas mismas. Nosotros aludiremos a este segundo de los sentidos respecto al vigente Derecho español, que, a pesar del título que le hemos dado a este trabajo, engloba en realidad a más de un ordenamiento jurídico debido a que la distribución territorial del poder introducida por la Constitución de 1978 va a determinar la existencia de diversos entes territoriales con autonomía política, al margen del propio Estado central. Esta autonomía política que se concreta en la capacidad legislativa de las llamadas comunidades autónomas. De esta forma, surge en cada una de las comunidades autónomas un ordenamiento jurídico propio.

Así las cosas, y siguiendo los esquemas que se usan en algunos estados federales, existe una suerte de supraordenamiento constitucional, que se conectaría al Estado global (a todo el conjunto del Estado), un ordenamiento del Estado central y un ordenamiento por cada una de las diecisiete comunidades autónomas. ${ }^{1}$ Proyectándose sobre todos ellos

1 La consideración de comunidades autónomas de Ceuta y Melilla, que supondría que el número se elevara a diecinueve, es objeto de discrepancias. Si bien tiene estatuto de autonomía carecen de capacidad legislativa. Por ello, y sin entrar en más detalles que no proceden en este lugar, nos inclinamos por no tenerlas por comunidades autónomas. 
estaría el Derecho de la Unión Europea, que no parece que pueda todavía dársele el calificativo de ordenamiento.

La referencia normativa en la que hay que fijarse es la Constitución de 1978, que ha desplazado al Código Civil en esta función de fijación de las fuentes jurídicas, aunque sin eliminarlo, por lo que se deberá tener en cuenta su regulación sobre el particular, a modo de complemento de lo recogido en el texto constitucional. La Constitución introdujo una serie de novedades respecto a lo que existía con anterioridad. Así, en primer lugar, ella misma es fuente del Derecho, la primera de las fuentes, que hace que la ley le aparezca subordinada. Además, introduce fuentes desconocidas en España hasta el momento: la ley orgánica (antes existía esa denominación pero conceptualmente era una cosa muy diferente), el Estatuto de Autonomía, y la ley de la Comunidad Autónoma. De igual forma, incorpora nuevos tipos de leyes estatales en el Art. $150^{\circ}$, prevé la posibilidad de tratados internacionales que cedan competencias soberanas (Art. 93०), modifica en ciertos aspectos las tradicionales relaciones entre ley y reglamento, y hace del principio de competencia el primero a tener en cuenta a la hora de discernir qué norma se aplica en un caso concreto. ${ }^{2}$ Asimismo, es necesario indicar que la enumeración que hace la Constitución de las fuentes no es algo cerrado, siendo posible que otras normas amplíen su número.

La relación entre las diversas fuentes se debe articular en torno al tradicional principio de jerarquía y, también, al de competencia. En virtud del primero, las normas de rango superior desplazan en la aplicación a las inferiores. Y la aplicación del segundo, conlleva que las normas dictadas por el órgano que tiene competencia en la materia se impongan a las que son producto de un órgano que carece de tales competencias.

El Tribunal Constitucional español, en el ejercicio de sus funciones, ha debido interpretar en un gran número de ocasiones, los preceptos que versan sobre las distintas fuentes. Para ello en España no existe,

2 Antes de 1978, a diferencia de lo que sucede en la actualidad, la primera de las fuentes era la ley, sólo el poder central emanaba normas legales y en los principios de resolución de los conflictos de aplicación de normas no se recogía el principio de competencia, usándose el de jerarquía, especialidad y temporalidad, los cuales hoy se utilizan cuando el de competencia no sirve para resolver la duda aplicativa. 
como ocurre en algún otro país, una específica atribución de interpretación obligatoria o auténtica por parte del órgano de justicia constitucional, sino que esta labor interpretativa la lleva a cabo el Tribunal Constitucional cuando resuelve los contenciosos que tiene atribuidos (que es lo que le sucede a cualquier órgano jurisdiccional, aunque la transcendencia y vinculación de las decisiones en uno y otro caso son bien diferentes). Las específicas características de los efectos de las sentencias constitucionales convierten a un buen número de las reflexiones realizadas por el Tribunal Constitucional en obligatorias para los poderes públicos. De ahí la importancia de reseñar cuál ha sido la doctrina sentada por este Tribunal en un tema de singular relevancia como el de las fuentes jurídicas. Ello no lo podemos hacer con ánimo exhaustivo porque excedería las pretensiones buscadas en el presente trabajo. Esperamos que las directrices generales que vamos a senalar den al lector una idea cabal de cuál es la situación en España de una cuestión muy compleja.

\section{La Constitución}

La Constitución de 1978 es la norma jurídica fundamental del actual Derecho español. No es una simple suma de principios o postulados políticos sino que presenta verdadero carácter jurídico y, por lo tanto, vinculante para todos, sean ciudadanos, sean poderes públicos (Art. 9.1). Su valor normativo está fuera de toda duda, como lo atestigua su eficacia derogatoria. En ocasiones, los preceptos constitucionales van a poder ser aplicados directamente por los operadores jurídicos para resolver los casos que se les presenten dado el alto grado de complitud y eficacia que presentan. En otros supuestos, será necesario un desarrollo ulterior por parte de los poderes constituidos, que no mengua la vinculación y la juridicidad de todo el articulado constitucional, que presenta siempre un mínimo de eficacia. ${ }^{3}$ En la jurisprudencia constitucional puede leerse que «la Constitución, lejos de ser un mero catálogo de principios de no inmediata vinculación y de no in-

3 Sobre clasificación de normas constitucionales con base en los criterios de la eficacia y de la aplicabilidad, permitasenos remitir a nuestro libro La inconstitucionalidad por omision. Teoría general, Derecho Comparado, el caso español, Civitas, Madrid, 1998, pp. 162 y ss. 
mediato cumplimiento hasta que no sea objeto de desarrollo por vía legal, es una norma jurídica, la norma suprema de nuestro ordenamiento» (STC 16/1982, de 28 de abril, FJ 1; también STC 80/1982, de 20 de diciembre, FJ 1$){ }^{4}$

La Constitución organiza el poder político, prevé la participación del pueblo en el mismo y concreta zonas exentas a tal poder. Este contenido, que puede resumirse en la suma de división de poderes, democracia y derechos fundamentales, es una de las razones de supremacía, pudiéndose añadir a la misma el propio origen de la Constitución en el pueblo actuando como poder constituyente. De este modo, la Constitución objetiva la soberanía. Además, la Constitución recoge las fuentes del Derecho, aparte de ser ella misma también fuente.

La Constitución aparece como una norma cualitativamente distinta, no sólo fundamental, sino también fundamentadora al ser la base de los diversos ordenamientos que proporciona unidad y coherencia a todo el conjunto. La supremacía exige un procedimiento agravado de reforma y un control de constitucionalidad que expulse a las normas que la contradigan, manifestaciones ambas de la superlegalidad formal y material que posee. La sujeción a la Constitución es una consecuencia obligada de su carácter de norma suprema, aunque esta sujeción se traduce en un deber de distinto signo para los ciudadanos y los poderes públicos. En efecto, «mientras los primeros tienen un deber general negativo de abstenerse de cualquier actuación que vulnera la Constitución [...], los titulares de los poderes públicos tienen además un deber general positivo de realizar sus funciones de acuerdo con la Constitución» (STC 101/1983, de 18 de noviembre, FJ 3).

\section{El ordenamiento del Estado central}

El presente ordenamiento tiene en el primer escalón jerárquico a la Constitución (salvo que se entienda que ésta forma parte de un

4 La jurisprudencia constitucional la citamos de la forma habitual en España: el primer número indica el número que supone esa sentencia en el año en que se produce, el segundo es el año, y luego el día y el mes. La expresión «sentencia del Tribunal Constitucional» la abreviamos STC. El fundamento jurídico lo abreviamos con FJ. La indicación del día y del mes sólo lo haremos en la primera cita de cada sentencia. 
supraordenamiento por encima del Derecho del Estado central y del de las comunidades autónomas, conectándose al Estado global). A continuación tenemos otro nivel integrado por las normas con rango de ley, subordinadas a la Constitución pero que no la ejecutan: ley orgánica, ley ordinaria, decreto-ley, decreto-legislativo, reglamentos parlamentarios y tratados internacionales. En tercer lugar, nos hallamos con los reglamentos administrativos, y en cuarto nivel, otras normas.

\subsection{La ley orgánica}

Esta norma, que en su momento generó polémica, se halla recogida en el Art. $81^{\circ}$ de la Constitución. En su definición hay que tener en cuenta un aspecto material y otro formal. En virtud del primero, que es el más importante, son leyes orgánicas las que versan sobre determinadas materias (desarrollo de los derechos fundamentales y libertades públicas, aprobación de estatutos de autonomía, régimen electoral general y demás materias previstas expresamente en otros artículos constitucionales ${ }^{5}$ ). El criterio formal del concepto es la necesidad de aprobación por mayoría absoluta en el Congreso de los Diputados en una votación final sobre el conjunto del proyecto, mayoría que también se exige para modificar o derogar una de estas normas. De esta forma, se podrán declarar inconstitucionales aquellas normas que no habiéndose aprobado como ley orgánica entren a regular materias reservadas a tal procedimiento.

La jurisprudencia constitucional ha subrayado la importancia del criterio material al indicar que el contenido de una ley orgánica sólo

5 Estos otros artículos que aluden a que cierta materia sea regulada por ley orgánica son el 8 (bases de la organización militar), 54 (Defensor del Pueblo), 55.2 (suspensión individual de derechos fundamentales), 57.5 (orden sucesorio de la Corona), 87.3 (iniciativa popular en las proposiciones de ley), 92.3 (modalidades de referéndum), 93 (autorización para celebrar cierto tipo de tratados internacionales), 104.2 (funciones, principios básicos de actuación y estatutos de las fuerzas y cuerpos de seguridad), 107 (composición y competencia del Consejo de Estado), 116 (estado de alarma, excepción y sitio), 122 (ley orgánica del Poder Judicial), 136 (composición, organización y funciones del Tribunal de Cuentas), 141.1 (alteración de los límites provinciales), 144 (supuestos especiales de constitución de comunidades autónomas), 148.1.22 (coordinación con policías locales), 149.1.29a (policía de las comunidades autónomas), 150.2 (leyes de transferencia o delegación), 151.1 (referéndum ratificación de la iniciativa autonómica), 157.3 (ejercicio de competencias financieras de las comunidades autónomas) y 165 (Tribunal Constitucional). 
será efectivamente orgánico si versa sobre las materias propias de la ley orgánica. Si ello no es así, el carácter de esos preceptos será el propio de ley ordinaria, pudiendo ser alterados por una de estas leyes ordinarias, sea del Estado central, sea de una comunidad autónoma. "La reserva de ley orgánica no puede interpretarse de forma tal que cualquier materia ajena a dicha reserva por el hecho de estar incluida en una ley orgánica haya de gozar definitivamente del efecto de congelación de rango y de la necesidad de una mayoría cualificada para su ulterior modificación, pues tal efecto puede y aún debe ser excluido por la misma ley orgánica o por sentencia del Tribunal Constitucional que declaren cuáles de los preceptos de aquella no participan de tal naturaleza». Y prosigue el Alto Tribunal: "Llevada a su extremo, la concepción formal de la ley orgánica podría producir en el ordenamiento jurídico una petrificación abusiva en beneficio de quienes en un momento dado gozasen de la mayoría parlamentaria suficiente y en detrimento del carácter democrático del Estado [...]. Por ello hay que afirmar que si es cierto que existen materias reservadas a ley orgánica, también lo es que las leyes orgánicas están reservadas a estas materias y que, por tanto, sería disconforme con la Constitución la ley orgánica que invadiera materias reservadas a la ley ordinaria" (STC 5/1981, de 13 de febrero, FJ 21). En otro lugar se completa lo acabado de mostrar indicando que el hecho de que «una ley orgánica pueda contener preceptos no orgánicos no significa [...] que sea suficiente la existencia de algún precepto de contenido orgánico para que pueda atribuirse a toda le ley dicho carácter» (STC 76/1983, 5 de agosto, FJ 51).

La reserva de ley orgánica no impide la "colaboración internormativa entre la fuente a favor de la cual la reserva se establece y otras fuentes de producción reconocidas en la Constitución, para alcanzar, de este modo, una disciplina integral y articulada del ámbito de que se trate" (STC 137/1986, de 6 de noviembre, FJ 3). Pero para disciplinar esta colaboración no son aplicables sin más, los criterios ordenadores de las relaciones entre ley ordinaria y reglamento, pues la ley orgánica está sujeta por un principio de especialidad, de tal modo que no podrá extender su normación más allá del ámbito que tiene reservado (ibidem).

Las materias de ley orgánica no pueden ser objeto de delegación legislativa a favor del Gobierno, ni de delegación a favor de las comisiones legislativas permanentes de las cámaras. Asimismo, la iniciativa legislativa popular no puede versar sobre dichas materias. 
La precisión de las materias reservadas a este tipo de norma ha sido labor de la jurisprudencia constitucional. Como derechos fundamentales y libertades públicas se entienden los contemplados en la Sección Primera del Capítulo II del Título I de la Constitución, es decir, artículos $15^{\circ}$ a $29^{\circ}$. Precisamente, y como recuerda la acabada de citar STC 76/1983, en su FJ 2, la denominación de la rúbrica de dicha sección coincide con la expresión que utiliza el Art. 81 ${ }^{\circ}$. Así las cosas, el principio de igualdad formal del Art. $14^{\circ}$ y la objeción de conciencia del Art. $30^{\circ}$ no son materia de ley orgánica (SSTC 76/1983 y 160/ 1987, de 27 de octubre). Vemos como el Tribunal Constitucional ha acudido a una interpretación literal en este lugar. Asimismo, se ha optado por una visión restrictiva del término "desarrollo» al concebirse éste como desarrollo directo de los derechos que comprende, por lo que no toda norma que incida o afecte a uno de los derechos de la aludida Sección Primera tiene que ser ley orgánica. Para apoyar esta postura se alega que la mayoría cualificada que exige el Art. $81^{\circ}$, al ser una excepción al principio democrático general de la mayoría simple, tiene que ser interpretada restrictivamente (SSTC 6/1982, de 22 de febrero, 65/ 1987, de 21 de mayo, y 160/1987). Lo contrario implica el riesgo de convertir a las Cortes en "constituyente permanente" con la proliferación de leyes orgánicas.

Como régimen electoral general se interpreta el conjunto de "normas electorales válidas para la generalidad de las instituciones representativas del Estado en su conjunto y en el de las entidades territoriales en que se organiza", o sea, provincias, municipios y comunidades autónomas (STC 38/1983, de 16 de mayo, FJ 3). Una ley será electoral cuando contenga un «núcleo central de la normativa atinente al proceso electoral, materia en la que se comprende lo relativo a quiénes pueden elegir, a quiénes se puede elegir, y bajo qué condiciones, para qué espacio de tiempo y bajo qué criterios organizativos desde el punto de vista procedimental y territorial" (STC 72/1984, de 14 de junio, FJ 4). Como se percibe, la postura que ha seguido aquí el Tribunal no es restrictiva, como en el caso anterior, pues no ha circunscrito esta materia a las elecciones generales legislativas (lo cual era una de las posibilidades interpretativas) sino que ha ido más allá según acabamos de mostrar.

La posición de la ley orgánica en el sistema de fuentes no se halla, todavía, totalmente clarificada. A nivel doctrinal la cuestión es bastante confusa, no estando claro si hay que acudir al principio de competen- 
cia o al de jerarquía. Parece que el principio de competencia es el más útil, de forma tal que la ley orgánica tiene el mismo nivel jerárquico que las demás normas con rango de ley diferenciándose por las materias que regula. Esto está claro con relación a la actividad de las Cortes Generales y del Tribunal Constitucional, aunque para otras cuestiones y operadores jurídicos funcionará la jerarquía, que se sustenta en el procedimiento agravado de aprobación de esta norma. La jurisprudencia constitucional ha empleado también los dos principios, y no sin cierta confusión. De este modo, en el FJ 20 de la ya citada STC 5/ 1981 se dice que un conflicto entre ley orgánica y ley ordinaria del Estado central se planteará si ambas leyes inciden sobre una misma materia, en cuya hipótesis la ley orgánica habrá de prevalecer sobre la ordinaria, ya que no puede ser modificada por ésta. Se piensa, por lo tanto, en una prevalencia que recuerda a la jerarquía. En el mismo lugar, se señala que si el conflicto se produce entre ley orgánica y ley autonómica, la resolución debe venir de la mano del principio de competencia "para determinar qué materias han quedado constitucional y estatutariamente conferidas a los órganos legislativos de las comunidades autónomas y cuáles corresponden a las Cortes Generales del Estadom. Pese a todo, por nuestra parte no dejamos de ver lo poco operativo de introducir la jerarquía en este lugar, pues con el mismo argumento de la mayoría cualificada de aprobación podría sostenerse que las leyes de armonización del Art. 150.3 son superiores a las orgánicas pues requieren mayoría absoluta en las dos cámaras. En la definición de ley orgánica el elemento material tiene un mayor protagonismo que el formal, lo que lleva indefectiblemente al principio de competencia.

\subsection{La ley ordinaria}

A pesar de que la Constitución no recoge una definición de ley ordinaria, sí se puede afirmar que en el ordenamiento español ésta posee un marcado carácter formal al considerarse como un acto de las Cortes Generales emanado de forma típica y solemne, o sea, a través del procedimiento legislativo. De esta forma, los clásicos caracteres de generalidad y abstracción que se solían predicar de la ley no resultan hoy en día de aplicación en España. No obstante, una ley singular, por exigencia del principio de igualdad, «debe responder a una situación excepcional» y también singular, siendo su canon de constitucionalidad la 
"razonabilidad y proporcionalidad de la misma al supuesto de hecho sobre el que se proyecta" (STC 166/1986, de 19 de diciembre, FJ 11).

Las leyes ordinarias pueden ser de dos tipos en función de los distintos pasos procedimentales que pueden seguir. Así, habrá leyes de pleno si son aprobadas por el pleno del Congreso y del Senado, y leyes de comisión si es una de las comisiones legislativas las que las aprueba. En efecto, las cámaras podrán hacer esta delegación a favor de las comisiones legislativas permanentes en virtud del Art. 75.2 de la Constitución, aunque el pleno de cada cámara puede recabar en cualquier momento el debate y la votación de cualquier proyecto o proposición de ley objeto de tal delegación. Al capítulo de los procedimientos legislativos especiales habría que añadir el procedimiento de lectura única y el procedimiento de urgencia.

A pesar de lo habitual que resulta hablar de reserva de ley, el sentido de la misma queda un tanto desvirtuado en tanto en cuanto no hay ninguna materia vedada a la ley. Lo que parecería más apropiado, sería hablar de reserva de procedimiento legislativo (de ley ordinaria, de ley orgánica). No hay, a diferencia, por ejemplo, del caso francés, unas materias reservadas al reglamento y otras a la ley. En cambio, sí existen ciertas cuestiones que tienen que regularse necesariamente por ley, sea ordinaria, sea orgánica, por lo que desde este punto de vista sí cobraría razón de ser hablar de reserva de ley para aludir a que ciertas materias deben regularse necesariamente por ley. Por ello, la reserva de ley, a pesar de no ser un criterio de atribución competencial al no haber materias vedadas a la ley, sí impone que la regulación de ciertas materias se haga por ese tipo de norma. De este modo, la libertad del legislador se reduce en la medida en que la ley debe contener suficientes referencias a la materia en cuestión para que la reserva legal no se vea vulnerada. No obstante, sí son posibles, y necesarias, remisiones a reglamentos para completar la regulación legal.

\subsection{EI decreto-legislativo}

El Gobierno puede dictar dos tipos de normas con fuerza de ley, aunque no son leyes en sentido formal: el decreto legislativo y el decretoley. La iniciativa del primero, y a diferencia de lo que ocurre en el decreto-ley, le pertenece a las Cortes Generales, que aparecen así como el sujeto habilitante que aprueba una ley de delegación, en virtud de la 
cual el sujeto habilitado, el Gobierno, podrá dictar ese acto con fuerza de ley denominado decreto legislativo. Este tipo de norma tiene como límite material las materias de ley orgánica.

La delegación debe realizarse de forma expresa para materia concreta, señalándose el plazo para su ejercicio y no permitiendo la subdelegación. Esta delegación, que se agota en un solo acto, puede tener lugar por una ley de bases, si se va a hacer un texto articulado, o por una ley ordinaria, cuando se trate de refundir varios textos legales en uno solo. La ley de bases debe delimitar con precisión el objeto y alcance de la delegación legislativa y los principios y criterios que han de seguirse en su ejercicio, además de no poder autorizar la modificación de la propia ley de bases ni permitir el dictado de normas retroactivas. Cuando la delegación se produzca por medio de una ley ordinaria habrá que determinar el ámbito normativo a que se refiere el contenido de la delegación, especificando si se va a formular un texto único o si se pretende regularizar, aclarar y armonizar los textos legales que han de ser refundidos (Art. $82^{\circ}$ de la Constitución, comentado el FJ 3 de la STC 205/1993, de 17 de junio).

El control de los decretos legislativos, que no sólo es de constitucionalidad material sino también de adecuación de la actuación del Gobierno a la habilitación recibida (STC 51/1982, de 19 de julio, FJ 1), le corresponde tanto al Tribunal Constitucional como a los tribunales ordinarios. Igualmente, las leyes de delegación pueden establecer fórmulas adicionales de control, que por lo normal es llevado a cabo por el Congreso de los Diputados. El Tribunal Constitucional actúa en tanto en cuanto nos hallamos ante normas con rango de ley. La intervención de los jueces ordinarios se produce en la medida en que son normas emanadas por el Gobierno, aunque no podrán entrar a controlar la constitucionalidad de esta norma ya que al tener rango de ley este control es competencia del Tribunal Constitucional. Lo que podrán hacer los jueces ordinarios es, por ejemplo, plantear una cuestión de constitucionalidad si se piensa que hubo extralimitación. Y también, como se dice en el FJ 3 del Auto del TC 69/1983, de 17 de febrero, pueden inaplicar «los decretos legislativos en lo que exceden de la delegación, o más propiamente, el no conferir al exceso el valor de ley". Por lo tanto, el control de los excesos de la delegación legislativa corresponde no sólo al TC sino también a la jurisdicción ordinaria (STC 47/1984, de 4 de abril, FJ 3). 
Hay que subrayar que no estamos ante un Poder Legislativo ordinario (esto es, parlamentario) sino delegado, que está encuadrado en un marco más estrecho que aquel en el que se mueven las Cortes Generales. Por ello, el control del decreto legislativo también se extiende a verificar el cumplimiento de los concretos requisitos formales que le son de aplicación. La inconstitucionalidad puede tener lugar por el ejercicio irregular de la delegación. En la misma línea de diferenciación entre ambas manifestaciones del poder legislativo hay que decir que actuaciones totalmente válidas si son adoptadas por el Poder Legislativo ordinario, pueden no serlo si las aprueba el Poder Legislativo delegado. De nuevo hay que traer a colación la STC 51/1982 y su FJ 1: "Un precepto determinado que si emanara directamente de las Cortes Generales no sería inconstitucional a no ser por oposición material a la Constitución, puede serlo si procede del Gobierno a través de un decreto legislativo por haber ejercitado aquel de modo irregular la delegación legislativa».

\subsection{El decreto-ley}

El decreto-ley es una norma provisional con fuerza de ley que dicta el Gobierno en supuestos de extraordinaria y urgente necesidad (Art. 86 ${ }^{\circ}$ ). Como vemos, a diferencia del caso anterior, la iniciativa le corresponde al Gobierno.

Así, el supuesto habilitante es la extraordinaria y urgente necesidad, cuya caracterización jurídica resultó discutida por la doctrina. De este modo, se dijo que era un concepto jurídico indeterminado, por lo que existía o no, siendo concretable a posteriori sin posibilidad de modulaciones. Por el contrario, otros sostuvieron que estábamos ante un supuesto de discrecionalidad, con lo cual el margen del Gobierno era mucho mayor y sólo encontraba su límite en un uso abusivo o arbitrario. La justificación del decreto-ley aunque no se volvía absoluta, sí aparecía con gran amplitud. El Tribunal Constitucional optó por la segunda postura, que, por cierto, no es nada restrictiva, indicando que «en principio, y con el razonable margen de discrecionalidad, es competencia de los órganos políticos determinar cuándo la situación, por consideraciones de extraordinaria y urgente necesidad, requiere el establecimiento de una norma por vía de decreto-ley" (STC 29/1982, de 31 de mayo, FJ 3 , a la que hay que sumar otras como las 6/1983, 51/ 
1983, de 14 de julio, y 111/1983, de 2 de diciembre). Lo que sí podrá hacer el Alto Tribunal es «en supuestos de uso abusivo o arbitrario, rechazar la definición que los órganos políticos hagan de una situación determinada como caso de extraordinaria y urgente necesidad, de tal naturaleza que no pueda ser atendida por la vía del procedimiento legislativo de urgencia" (de nuevo, FJ 3 de la STC 29/1982). Pero este control es un control jurídico que, como se indica también en esta última sentencia, verifica si el decreto-ley guarda relación con la situación que se trata de afrontar. Si no modifica de manera instantánea la situación jurídica existente "difícilmente podrá predicarse la justificación de la extraordinaria y urgente necesidad" (ibidem). Realmente, el Tribunal Constitucional no ha visto el decreto-ley como una fuente realmente excepcional, sólo viable ante una necesidad absoluta, sino como un instrumento normativo "para dar respuesta a las perspectivas cambiantes de la vida actual" (STC 6/1983, FJ 5). A lo que se añade en el mismo lugar que la justificación procede de una «necesidad relativa respecto de situaciones concretas de los objetivos gubernamentales, que, por razones difíciles de prever, requieren una acción normativa inmediata en un plazo más breve que el requerido por la vía normal o por el procedimiento de urgencia para la tramitación parlamentaria de las leyes».

Los límites materiales del decreto-ley, o sea, las materias que no pueden ser afectadas por este tipo de norma, so pena de ser declarada inválida, son las instituciones básicas del Estado, los derechos, deberes y libertades del Título I de la Constitución, el régimen de las comunidades autónomas y el Derecho Electoral general. La primera de estas materias ha sido entendida como los elementos estructurales, esenciales o generales de la organización y funcionamiento de las mismas, no afectando, en cambio, «a cualesquiera otros aspectos accidentales o singulares de las mismas» (STC 60/1986, de 20 de mayo, FJ 4); los derechos del Título I como los que integran los capítulos I y II de dicho Título pero no los del Capítulo III (principios rectores de la política social y económica); ${ }^{6}$ y el régimen de las comunidades autónomas como

6 En la STC 111/1983 puede leerse que hay que tener en cuenta la colocación del derecho afectado «en el texto constitucional dentro de las diversas secciones y capítulos de su Título I, dotados de mayor o menor rigor protector a tenor del Art. 53 de la Constitución" (fundamento jurídico 8). 
el sistema de distribución de competencias, o sea, "el ámbito que la Constitución reserva a determinadas leyes para delimitar las competencias del Estado y las diferentes comunidades autónomas o para regulara o armonizar el ejercicio de las competencias de éstas" (SSTC 29/1986, de 20 de febrero, y 23/1993, de 21 de enero, FJ 2) ${ }^{7}$.

Una dificultad añadida a la interpretación de este artículo ha sido la concreción del término "afectar", que no se ha entendido de manera literal, porque de lo contrario el decreto-ley quedaría reducido a la nada pues de una u otra forma casi todas las materias acaban «afectando" a uno de los derechos del Título I, con lo que esta interpretación quedaría reducida ad absurdum (STC 111/1983, de 2 de diciembre, FJ 8). Así las cosas, se ha interpretado en este caso que "afectar" aludía a la regulación del régimen jurídico general de uno de estos derechos o de su contenido esencial, cuestiones ambas que escapaban de las posibilidades del decreto-ley (SSTC 111/1983, 6/1983 y la aún no citada $3 / 1988$, de 21 de enero). Lo mismo se ha dicho en cuanto al régimen de las comunidades autónomas, que se vería afectado por una delimitación directa y positiva de las competencias mediante instrumento normativo, y no por cualquier regulación que indirectamente «incida" en las competencias autonómicas (STC 23/1993, FJ 2).

El decreto-ley debe ser sometido en un plazo de treinta días desde su promulgación al Congreso de los Diputados para que éste se pronuncie acerca de su convalidación o derogación. Igualmente, en este plazo el decreto-ley puede ser tramitado como proyecto de ley por el procedimiento de urgencia. Aunque en teoría podría pensarse que ambas vías son alternativas (en el FJ 2 de la STC 29/1982 se dice que nada se opone a una interpretación de este tipo), en realidad son compatibles, siendo la práctica habitual que primero se convalide y después se tramite como proyecto de ley. En realidad una u otra opción tienen consecuencias muy diferentes porque mientras con la convalidación no cambia su naturaleza jurídica y sigue siendo decreto-ley, aunque haya perdido la provisionalidad, ${ }^{8}$ el éxito en la tramitación como proyectos

7 A la expresión "Derecho electoral general" se le puede hacer extensiva la interpretación del "régimen electoral general" de la ley orgánica, con lo que el decreto-ley no podría entrar a regular las consultas de alcance territorial general, independientemente de la naturaleza política de la elección (STC 38/1983).

8 Por ello el Tribunal Constitucional en su sentencia 6/1983 (FJ 5) ha llegado a decir que lo que la Constitución llama "convalidación" es "más genuinamente una homologación 
de ley lo convierte en ley formal del Parlamento (STC 29/1982, también FJ 2), que ya no estará sujeta a los específicos límites materiales del decreto-ley. Estos límites siguen rigiendo para el decreto-ley convalidado y pueden dar lugar a la declaración de nulidad del mismo por una extralimitación que la convalidación no soluciona.

\subsection{Los reglamentos parlamentarios}

La capacidad de autoorganización de las Cámaras posibilita que se dicten las normas que han de regirlas completando la regulación constitucional (Art. $72^{\circ}$ ). Surge así un tipo de normas que tradicionalmente se han venido llamando reglamentos, a pesar de atribuírseles rango similar al de la ley (STC 118/1988, de 20 de junio, FJ 3). Esta denominación de reglamento no debe confundirnos ya que su naturaleza jurídica es muy diferente a la del reglamento dictado en uso de la potestad reglamentaria que ostenta el Gobierno, que sí es una norma inferior a la ley.

Tanto el Congreso de los Diputados como el Senado tienen sus respectivos reglamentos, que fueron aprobados de manera individual por cada Cámara. Igualmente, la Constitución prevé un reglamento para las Cortes Generales destinado a regir en las sesiones conjuntas que puedan existir, reglamento este, por cierto, que todavía no ha sido dictado. Los reglamentos parlamentarios regulan, con sujeción a la Constitución y directamente incardinados en la misma, la organización y funcionamiento de las cámaras, «en el que ha de incluirse lógicamente la constitución del órgano como tal» (STC 101/1983, FJ 3).

En el FJ 2 de la STC 139/1988, de 8 de julio, se nos dice que no estamos ante "una disposición de categoría inferior a la ley sino, antes bien, de una norma que de acuerdo con la reserva constitucional establecida, goza de fuerza de ley y que, asimismo, por proceder del Poder Legislativo, posee valor de ley". Aún así, no parece correcto técnicamente atribuirle la misma fuerza activa y pasiva que tiene una ley en sentido formal, aunque sí presenta valor de ley. La jurisprudencia constitucional (STC 99/1987, de 11 de junio, FJ 1) también afirma que estas normas deben formar parte del parámetro de constitucionalidad

respecto a la existencia de la situación de necesidad justificadora de la iniciativa legislativa encauzada por ese caminom. 
por la invulnerabilidad de las reglas de procedimiento que contienen frente a la acción del legislador y, sobre todo, "por el carácter instrumental que esas reglas tienen respecto de uno de los valores superiores de nuestro ordenamiento, el del pluralismo político". De ahí se colige que «la inobservancia de los preceptos que regulan el procedimiento legislativo podría viciar de inconstitucionalidad la ley, cuando esa inobservancia altere de modo sustancial el proceso de formación de voluntad en el seno de las Cámaras».

\subsection{El tratado internacional}

En la Constitución se diferencian tres tipos de tratados internacionales. Los primeros son los del Art. 93º, que sirven para atribuir a una organización internacional el ejercicio de competencias soberanas. Esta fue la vía utilizada para la incorporación a la Unión Europea, que ahora no nos interesa. Los otros dos tipos de tratados se encuentran en el Art. $94^{\circ}$, que ya no presenta una función de habilitación como el anterior sino de recepción o incorporación. En este Art. $94^{\circ}$ tenemos, por un lado, unos tratados que requieren autorización previa de las Cortes Generales para que el Estado preste su consentimiento a los mismos, $y$, por otro, los restantes tratados que no precisan de tal autorización, de los cuales sólo se informará a las Cortes una vez concluidos. La diferencia entre unos y otros es la materia sobre la que versen.

Los tratados sólo pueden ser derogados, modificados o suspendidos siguiendo la forma estipulada en los propios tratados o de acuerdo con las normas generales del Derecho Internacional (Art. 96). Por lo tanto, tienen fuerza pasiva frente a la ley, o sea, resisten frente a ella. Por otro lado, la fuerza activa frente a la ley, es decir, la posibilidad de que modifiquen una ley, sólo parece que puede predicarse de los que requieren autorización de las Cortes Generales. Para explicar la relación entre tratados y demás normas con rango de ley se suele acudir al principio de competencia, que permite postular la prioridad en la aplicación de los tratados.

9 Se trata de los tratados de carácter político, de carácter militar, que afecten a la integridad territorial del Estado o a los derechos y deberes fundamentales establecidos en el Título I de la Constitución, que impliquen obligaciones financieras para la Hacienda Pública y los que supongan modificación o derogación de alguna ley o exijan mediadas legislativas para su ejecución. 
El Art. $95^{\circ}$ de la Constitución prevé un control previo de constitucionalidad de los tratados internacionales, con el que se pretende impedir la creación de derecho inconstitucional e indicar el camino correcto para la creación de derecho a través del tratado en cuestión. La decisión del Tribunal, que adopta la forma de declaración y no de sentencia, es vinculante, por lo que se impone a todos los poderes públicos sin excepción, de tal manera que, una vez emitido su parecer, hay que seguir la vía que en él se indica para que la prestación del consentimiento del Estado sea constitucionalmente correcta (Declaración del TC de 1 de julio de 1992, FJ 1). Si se concluye que el tratado contradice a la Constitución, dicho tratado sólo podrá ratificarse si hay una previa revisión constitucional. De este modo, la Constitución ve garantizada, a través del procedimiento de reforma previsto por ella misma, su primacía (ibidem).

\subsection{El reglamento}

En un nivel jerárquicamente inferior a las normas con rango de ley nos encontramos con el reglamento, una norma escrita de carácter general dictada por el Gobierno. La ley aparece como la fuente primaria y el reglamento como la secundaria, en tanto en cuanto es obra de un órgano, el Gobierno, que no representa al pueblo español como sí lo hacen las Cortes Generales. Las relaciones entre ambas son verticales y univocas. El reglamento también presenta, por lo tanto, un carácter formal, como el producto normativo típico del Gobierno. El Gobierno ejerce la potestad reglamentaria de acuerdo con la Constitución y las leyes (Art. 97\%).

Como se indicó más arriba, la reserva de ley exige que la regulación de determinadas materias se haga por norma con rango de ley. Sin embargo, ello no impide las remisiones a reglamentos para completar y ejecutar semejante regulación (STC 83/1984, de 24 de julio). La lógica de una buena técnica normativa así lo reclama para que a medida que se desciende en la escala jerárquica se vaya entrando en la regulación de aspectos más concretos. Las remisiones a normas reglamentarias no deben hacer "posible una regulación independiente y no claramente subordinada a la ley, lo que supondría una degradación de la reserva (de ley) formulada por la Constitución a favor del legislador» (otra vez, STC 83/1984). Y en el mismo lugar se añade: «Esto se tra- 
duce en ciertas exigencias en cuanto al alcance de las remisiones o habilitaciones legales a la potestad reglamentaria, que pueden resumirse en el criterio de que las mismas sean tales que restrinjan efectivamente el ejercicio de esa potestad a un complemento de la regulación legal que resulte indispensable por motivos técnicos o para optimizar el cumplimiento de las finalidades propuestas por la Constitución o por la propia ley".

Igualmente, cuando el legislador remite una materia al reglamento puede en cualquier momento regularla él mismo, pues el Derecho español no reconoce el principio de reserva reglamentaria (STC 18/1982, de 4 de mayo, FJ 3). En efecto, «lo que en la Constitución no existe es lo que podríamos denominar reserva reglamentaria, esto es, la imposición de que determinadas cuestiones hayan de ser reguladas por norma reglamentaria y no por otras con rango de ley» (STC 5/1981, FJ 21).

El Tribunal Constitucional casi no ha entrado en el análisis del reglamento, cosa por otra parte normal si se tiene en cuenta que el control de este tipo de norma pertenece a los jueces ordinarios, quedando al juez constitucional el control de las normas con rango de ley, para cuya declaración de nulidad ostenta monopolio.

La Constitución sólo atribuye la potestad reglamentaria al Gobierno, aunque también se viene admitiendo el dictado de este tipo de normas a órganos inferiores, si bien con un alcance interno. Así, podría pensarse que existe una potestad reglamentaria ad extra y otra ad intra. ${ }^{10}$ No obstante, se encuentra generalmente aceptado que no existen reglamentos independientes, desconectados de la ejecución de una determinada ley, salvo en los aspectos meramente organizativos. De este modo, en principio los reglamentos tendrán un carácter general y ejecutivo, estando «directa y concretamente ligados a una ley, a un artículo o artículos de una ley o a un conjunto de leyes, de manera que dicha ley es completada, desarrollada, pormenorizada, aplicada y cumplimentada o ejecutada por el reglamenton (STC 18/1982, FJ 4). Junto a estos, dicha sentencia menciona los reglamentos de organización que no aparecen necesariamente como complementarios de la ley y «que, todo lo más, alcanzan a normar las relaciones de la Administración con los administrados en la medida en que ello es instrumentalmente necesa-

10 El Tribunal Supremo ha distinguido con claridad estos dos tipos de potestad reglamentaria (Sentencia de la Sala Tercera de 11 de abril de 1981). 
rio por integrarse éstos de una u otra forma en la organización administrativa, pero no los derechos y obligaciones de éstos en aspectos básicos o con carácter general». La Ley No 50/1997, de 17 de noviembre, reguladora del Gobierno, distingue en su Art. 23.3 los reglamentos aprobados por real decreto (sea del Presidente del Gobierno, sea del Consejo de Ministros) y los aprobados por orden ministerial, con lo que parece ganar fuerza esa diferenciación entre dos tipos de reglamentos, que han venido llamándose reglamentos ejecutivos o jurídicos (sic.) y reglamentos administrativos $\mathbf{u}$ organizativos.

\section{Los ordenamientos de las Comunidades Autónomas}

El Estado complejo creado por la Constitución de 1978 supuso la aparición de unos entes territoriales dotados de autonomía política que iban a tener un Derecho propio en aquellas materias sobre las que asumieran competencias. Puede así afirmarse que cada Comunidad Autónoma tiene un ordenamiento o subordenamiento jurídico que, evidentemente, entra en contacto con el ordenamiento jurídico estatal y con los demás ordenamientos autonómicos. La cabeza de todos ellos es la Constitución. Con el Estado Autonómico aparecen nuevas fuentes (el Estatuto de Autonomía y las leyes de las comunidades autónomas), nuevos tipos de leyes estatales (la ley marco de delegación de competencias legislativas, la ley orgánica de transferencias y la ley de armonización -Art. $150^{\circ}$-), y se modifican las tradicionales relaciones entre ley y reglamento. Asimismo, en los ordenamientos autonómicos se reproducen esquemas ya vistos para el ordenamiento del Estado central, como en lo que concierne al reglamento parlamentario, a los decretos legislativos o a la potestad reglamentaria de los gobiernos o de los consejos ejecutivos autonómicos. En ello ya no vamos a entrar. Lo que hay que subrayar es que, a diferencia de lo que ocurre con el decreto legislativo, no está previsto para ninguna comunidad la figura del decreto-ley.

\subsection{El Estatuto de Autonomía}

El Estatuto de Autonomía es la norma institucional básica de cada comunidad autónoma (Art. 147\%). En ella se recogen las reglas funda- 
mentales de sus órganos y se asumen las competencias autonómicas de acuerdo con el principio dispositivo, o sea, voluntariamente dentro del techo establecido por la Constitución. Como se lee en la STC 18/ 1982, "para determinar si una materia es de la competencia del Estado o de la comunidad autónoma, resulta en principio decisorio el texto del Estatuto de Autonomía de la Comunidad Autónoma, a través del cual se produce la asunción de competencias». Este tipo de norma no es expresión de soberanía sino de autonomía por lo que está claramente subordinada a la Constitución.

Desde un punto de vista formal es una ley orgánica puesto que es por ley orgánica como se aprueban. No obstante, en realidad es, sin duda, mucho más, dadas las profundas diferencias que presenta frente a la ley orgánica en cuanto a la iniciativa para su elaboración, su contenido predeterminado por la Constitución (arts. $147^{\circ}$ y $152^{\circ}$ ), su tramitación en algunos casos, y su especial rigidez. Es evidente que aunque sean aprobados por ley orgánica, no se sitúan en el mismo lugar que dicho tipo de ley. Sin embargo, esa aprobación por ley orgánica hace que el Estatuto de Autonomía no sólo forme parte del ordenamiento de su respectiva comunidad sino también del ordenamiento del Estado central (la ley orgánica es una fuente que sólo se encuentra en este último ordenamiento).

El carácter materialmente constitucional que presentan los estatutos hace que éstos formen parte del llamado bloque de constitucionalidad, que es el parámetro de validez de las leyes. Puede, así, afirmarse que estamos ante una norma complementaria de la propia Constitución. Las relaciones entre los estatutos de autonomía y las leyes estatales están presididas por el principio de competencia. Las que se producen entre los estatutos y las leyes de sus respectivas comunidades, por el principio de jerarquía.

\subsection{La ley autonómica}

La Constitución no ha establecido distintos tipos de leyes autonómicas, por lo que hay que entender que sólo existen leyes ordinarias aprobadas por mayoría simple, aunque algún Estatuto y alguna aportación doctrinal maticen mucho esta afirmación. El concepto de ley autonómica no es, como le ocurre a la ley estatal, simplemente formal pues también presenta una dimensión material. En efecto, es una norma 
aprobada por la Asamblea Legislativa de una comunidad autónoma a través del correspondiente procedimiento legislativo que, además, debe versar sobre materias cuya competencia legislativa ha sido asumida por la comunidad autónoma. Hay una serie de principios que actúan como límites para estas normas, a saber: la unidad de la nación española (Art. $2^{\circ}$ ); el principio de solidaridad entre las nacionalidades y regiones que integran España (arts. $2^{\circ}$ y $138^{\circ}$ ); igualdad de derechos y obligaciones en cualquier parte del territorio estatal (Art. 139.1); libertad de circulación y establecimiento de las personas y libre circulación de bienes en todo el territorio español (Art. 139.2). La relación que se produce entre las leyes autonómicas y las estatales se rige por el principio de competencia, no jerarquía.

Estas leyes pueden ver suspendida su aplicación ante la impugnación del Gobierno central en el Tribunal Constitucional, el cual deberá en un plazo máximo de cinco meses ratificar o levantar tal suspensión (Art. 161.2).

\subsection{Las relaciones entre ley y reglamento en el Estado Autonómico}

El Estado Autonómico ha modificado las tradicionales relaciones que se venían produciendo entre la ley y el reglamento. Estas relaciones estaban presididas por el principio de jerarquía, que colocaba a la ley por encima del reglamento, que, de contradecirla, sería declarado inválido. Ello sigue siendo así en el interior de cada ordenamiento. No obstante, cuando la relación es entre ordenamientos, el principio a tener en cuenta es el de competencia. De esta forma, un reglamento autonómico tiene prioridad aplicativa respecto a una ley estatal cuando verse sobre una materia de competencia exclusiva de esa comunidad autónoma. Asimismo, una ley autonómica puede estar condicionada por un reglamento del Estado central cuando a éste le corresponda dictar la normativa básica sobre la materia en cuestión y a la comunidad la normativa de desarrollo (la definición de lo básico la realizan las Cortes Generales -órgano central- mediante ley, que puede ser complementada por el propio Gobierno central a través de su potestad reglamentaria ${ }^{11}$ ).

11 La definición de legislación básica no impide la entrada del reglamento que ejecuta la ley. La búsqueda de uniformidad en la regulación de una materia requiere que el término "legislación" incluya a veces reglamentos. 


\section{El Derecho comunitario}

El Art. $93^{\circ}$ de la Constitución, como se indicó más arriba, posibilita la celebración de tratados internacionales que atribuyan a una organización internacional el ejercicio de competencias soberanas. Esta previsión fue utilizada para la incorporación en 1985 de España a lo que hoy es la Unión Europea. La Ley Orgánica 10/1985, de 2 de agosto, fue la que autorizó el tratado de adhesión de España a la Comunidad Europea, determinando la vigencia en España del Derecho Comunitario, sea primario, sea derivado. La Unión Europea es una organización internacional sui generis, lo cual ha llevado al Tribunal Constitucional a afirmar que "cuando España actúa en el ámbito de las Comunidades Europeas lo está haciendo en una estructura jurídica que es muy distinta de la tradicional de las relaciones internacionales" (STC 165/1994, de 26 de mayo).

El alcance del aludido Art. $93^{\circ}$ fue precisado por la STC 28/1991, de 14 de febrero, en su FJ 4. En ella se afirma que dicho artículo, a pesar de su carácter orgánico-procedimental («se limita a regular el modo de celebración de una determinada clase de tratados internacionales»), es el fundamento constitucional último de la vinculación de España al Derecho Comunitario ya que es a través de la ley orgánica, expresión de la soberanía estatal, como se produce la aceptación de dicha vinculación. Así las cosas, el Derecho Comunitario no posee rango y fuerza constitucionales, ni su infracción por una disposición española entraña "a la vez conculcación del citado Art. 93\%". Ésta es la línea que sigue la decisión de 1 de julio de 1992, dictada por el Tribunal a raíz de la ratificación del Tratado de Maastricht, en donde se subraya, en el FJ 4, que el Art. $93^{\circ}$ no permite disponer de la Constitución "contrariando o permitiendo contrariar sus determinaciones, pues ni el poder de revisión constitucional es una "competencia" cuyo ejercicio fuera susceptible de cesión, ni la propia Constitución admite ser reformada por otro cauce que no sea [...] a través de los procedimientos» en ella establecidos "y mediante la modificación expresa de su propio texto». La integración en la Unión Europea sólo puede llevarse a cabo dentro de los límites fijados por el constituyente.

El Derecho Comunitario es un Derecho que no es ni estatal ni internacional, sino que puede catalogarse como de supraestatal. Se inserta en el ordenamiento estatal perturbándolo, o sea, desplazando de 
su aplicación al Derecho interno, sea del Estado central, sea de una comunidad autónoma. En opinión de la jurisprudencia constitucional, "constituye un ordenamiento jurídico propio, integrado en el sistema jurídico de los estados miembros y que se impone a sus órganos jurisdiccionales" (STC 28/1991). Este orden jurídico, para el conjunto de los Estados que integran la Unión Europea, puede considerarse a ciertos efectos como «interno" (STC 165/1994).

El Derecho Comunitario tiene un efecto directo y una primacía, que no hay que entender en el sentido de superioridad jerárquica sino como una preferencia en la aplicación. Respecto a la Constitución, este Derecho es, claro está, infraconstitucional (SSTC 28/1991 y 45/1996, de 25 de marzo) o "no constitucional" (STC 180/1993, de 31 de mayo), no integrando "el canon de constitucionalidad bajo el que hayan de examinarse las leyes del Estado español" (STC 28/1991, FJ 5). Por ello, el recurso de amparo sólo procede por lesiones de los derechos fundamentales enunciados en los artículos $14^{\circ}$ a $30^{\circ}$ de la Constitución española, no pudiendo plantearse ante eventuales vulneraciones del Derecho Comunitario, cuyas normas «únicamente podrían llegar a tener, en su caso, el valor interpretativo que a los tratados internacionales" les asigna la Constitución en el Art. 10.2 (STC 64/1991, de 22 de marzo, FJ 4). Las normas comunitarias relativas a las materias sobre las que incide la disposición o acto recurrido en amparo, son un elemento más para verificar la consistencia o inconsistencia de aquella infracción. Lo mismo que sucede con la legislación interna en las materias ajenas a la competencia de la Comunidad (SSTC, entre otras, 145/1991, de 1 de julio, 229/1992, de 14 de diciembre, y 137/1995). $\mathrm{Y}$ también en el campo del recurso de amparo el Alto Tribunal ha señalado su competencia para controlar de modo indirecto el Derecho Comunitario cuando al aplicarlo una autoridad española vulnera un derecho fundamental protegible en amparo: «En la medida en que se impugne en amparo un acto del poder público que, habiendo sido dictado en ejecución del Derecho Comunitario europeo, pudiera lesionar un derecho fundamental, el conocimiento de tal pretensión corresponde a esta jurisdicción constitucional con independencia de si aquel acto es o no regular desde la estricta perspectiva del ordenamiento comunitario europeo" (STC 64/1991, FJ 4). La justificación del presente razonamiento está en que "la cesión del ejercicio de competencias en favor de organismos supranacionales no implica que las autoridades 
nacionales dejen de estar sometidas al ordenamiento interno cuando actúan cumpliendo obligaciones adquiridas frente a tales organismos, pues también en estos casos siguen siendo poder público que está sujeto a la Constitución y al resto del ordenamiento jurídico español».

Los problemas que más importancia pudo haber generado la entrada del Derecho Comunitario se refieren a los derechos fundamentales y a la distribución de competencias entre el Estado y las comunidades autónomas. El diferente grado de desarrollo del reconocimiento y protección de los derechos fundamentales en los diversos estados y en el Derecho Comunitario motivó en su momento, y en otras latitudes, los conflictos en el primer caso, como queda reflejado, por ejemplo, en la Sentencia del Tribunal Constitucional alemán de 29 de mayo de 1975. La evolución del proceso de integración europea ha ido superando este problema de manera tal que hoy por hoy no parece probable que en esta cuestión pueda darse un choque entre el Derecho español y el Comunitario. En cuanto a la distribución de competencias entre el Estado y las comunidades autónomas, el Tribunal Constitucional ha sentado el principio de la irrelevancia del Derecho Comunitario en esta cuestión, que "no se ha visto alterada en ningún caso por la integración de España en la Unión Europea, ni puede serlo como consecuencia de su derecho derivado" (STC 147/1996, de 19 de septiembre, FJ 3, en donde se remite a las SSTC 252/1988, de 20 de diciembre, 76/1991, de 11 de abril, 79/1992, de 28 de mayo, y 80/1993, de 8 de marzo). De esta forma, «la ejecución del Derecho Comunitario corresponde a quien materialmente ostente la competencia, según las reglas del Derecho interno, puesto que no existe una competencia específica para la ejecución del Derecho Comunitario» (SSTC 79/1992, FJ 1, $326 / 1991$, FJ 9). Evidentemente, hay que añadir a lo dicho que los actos y normas de la Unión Europea pueden afectar, por supuesto, al ejercicio de las competencias (STC 165/1994), que es una cosa diferente a incidir en el sistema de distribución de las mismas.

Como se ve, el Derecho Constitucional no se ve afectado por la penetración del Derecho Comunitario. Sí, en cambio, el Derecho infraconstitucional, frente al cual prevalece el Derecho Comunitario, que presenta, como se dijo, eficacia directa (STC 130/1995, de 11 de septiembre). No obstante, el Tribunal Constitucional no garantiza la supremacía del Derecho Comunitario ya que éste "tiene sus propios órganos de garantía entre los cuales no se cuenta este Tribunal Consti- 
tucional» (STC 28/1991, FJ 7). Por ello, dicho Tribunal entiende que el no planteamiento de una cuestión prejudicial por un órgano jurisdiccional español ante el Tribunal de Justicia de las Comunidades Europeas no implica la vulneración del derecho a la tutela judicial efectiva que consagra la Constitución (SSTC, entre otras, 111/1993, de 25 de marzo, 143/1994, de 9 de mayo, 45/1996, 70/1997, de 10 de abril). En suma, la tarea de garantizar la recta aplicación del Derecho Comunitario «por los poderes públicos nacionales es una cuestión de carácter infraconstitucional y por lo mismo excluida [...] de los procesos constitucionales" (STC 65/1991, de 22 de marzo, FJ 4).

\section{Selección bibliográfica}

Alzaga VillaAmil, Oscar (coord.)

1996-99 Comentarios a la Constitución española de 1978, doce tomos, Madrid, EDERSA.

Derecho Político español según la Constitución de 1978.

1997 Sistema de fuentes, Madrid, Centro Ramón Areces.

Carrillo, Marc

1987 "El decreto-ley: ¿excepcionalidad o habitualidad?», Revista de las Cortes Generales, No 11, pp. 47 y ss.

Chofre Sirvent, J. F.

1994 Significado y función de las leyes orgánicas, Madrid.

Colom Pastor, Bartolomeu

1984 «Reglamento independiente y potestad reglamentaria: cinco años de experiencia constitucional", Revista Española de Derecho Administrativo, No 40-41, pp. 239 y ss.

Espin Templado, E.

1985 "Separación de poderes, delegación legislativa y potestad reglamentaria en la Constitución española», Revista de las Cortes Generales, No 6, pp. 167 y ss. 
García de ENTERRIA, Eduardo

1991 La Constitución como norma y el Tribunal Constitucional, Madrid, Civitas, $3^{a}$ ed.

García de Enterría, Eduardo y Tomás Ramón Fernández Rodríguez Curso de Derecho Administrativo, Vol. I, Madrid, Civitas.

Muñoz MaChado, Santiago

1982-84 Derecho Público de las comunidades autónomas, dos volúmenes, Madrid, Civitas, .

Otto y Pardo, Ignacio de

1987 Derecho Constitucional. Sistema de fuentes, Barcelona, Ariel.

PÉREZ RoYo, Javier

1988 Las fuentes del Derecho, Madrid, Tecnos, $4^{\mathrm{a}} \mathrm{ed}$.

Pérez TRemps, Pablo

1994 Constitución española y Comunidad Europea, Madrid, Civitas.

Portero Molina, José Antonio

1997 Constitución y jurisprudencia constitucional, Valencia, Tirant lo blanch, $3^{\mathrm{a}}$ ed.

RUBio LLORENTE, Francisco

1983 "Rango de ley, fuerza de ley, valor de ley», Revista de Administración Pública, no 100-102, pp. 417 y ss.

Santaolalla, Fernando

1994 «En torno a las leyes orgánicas: comentario a la sentencia del Tribunal Constitucional 25/1984, de 23 de febrero", Revista de Administración Pública, No 104, pp. 333 y ss. 